\title{
TITLE:
}

\section{$<$ Note $>$ A Live Birth by a Primiparous Female Chimpanzee at the Budongo Forest}

$\operatorname{AUTHOR}(\mathrm{S})$ :

Kiwede, Zephyr T.

\section{CITATION:}

Kiwede, Zephyr T.. <Note> A Live Birth by a Primiparous Female

Chimpanzee at the Budongo Forest. Pan Africa News 2000, 7 (2): 23-25

ISSUE DATE:

2000-12

URL:

http://hdl.handle.net/2433/143554

RIGHT:

Copyright (C) Pan Africa News. 


\title{
$<$ NOTE
}

\section{A Live Birth by a Primiparous Female Chimpanzee at the Budongo Forest}

\author{
Zephyr T. Kiwede \\ Budongo Forest Project
}

The Sonso community of chimpanzees in the Budongo Forest Reserve (Uganda) currently comprises 49 individuals. During October 1998, pregnancy tests were carried out on two sub-adult females of the community. One of them (KY) was found to be pregnant on 7 Oct 1998 (Pebsworth unpublished). Particular attention was focused on this individual. On 30 Dec 1998, the birth of the infant was observed, and observations continued on the days following the birth.

\section{Description of the Birth}

At 07:30 of 30 Dec 1998, chimpanzees of the Sonso community were heard calling. Many chimpanzees were found feeding on ripe figs (Ficus mucuso). A nulliparous female named KEWAYA (KY) was sitting on a branch of the tree at a height of 30 metres above the ground just below the crown. At 08:07 KY was not feeding but appeared to be in pain. At 08:38 she pushed her left hand into her vagina for 40 seconds. The right hand of $K Y$ was deformed and lacking functionality due to a snare injury. When she removed the hand, it was wet. She licked her fingers. At 08:42 she pushed the hand again into her vagina. When she removed it, a quantity of fluid came out from the vagina. It was assumed that the amniotic sac had broken. She moved 1/2 metre on the same branch and sat, then stood up quadrupedally, then moved back, sat again and again moved back. She pushed her hand into her vagina several times. At 08:50 while removing the 
hand from the vagina, fluid emerged again. She remained "unsettled" and pushed her left hand into her vagina. At 08:55 when she removed the hand, some more fluid (a smaller amount than before) came out of the vagina. At this time she stopped pushing her hand into her vagina, but she placed/pressed her hand on her vagina as if she was waiting for something. KY repeatedly touched her vagina and moved about in the tree, changing from one branch to another. At 09:12 she started showing abdominal contractions with the right (functionless) hand placed on the vagina.

At 09:15 other individuals of the Sonso community, KG (adult female) with her offspring KD (juvenile male) and KT (infant female) came onto the same branch. KG moved in the direction of KY. KG sat $1.5 \mathrm{~m}$ away from KY. At 09:20 KY changed position facing $K G$ 's side. At this time $K Y$ was thought to be in pain and she kept her left hand on her vagina. At 09:22 the vagina opened widely: the infant's head was seen to come out first. The infant emerged fully at 09:23:20 and $\mathrm{KY}$ caught it with her left hand. She immediately pulled the infant onto her belly and hugged it. 4 sec from the birth of the infant, blood started to flow for about $5 \mathrm{sec}$. At 09:26 a juvenile male $\mathrm{KD}$ came close to see the newborn. KY did not pay attention to KD. At 09:40 the placenta emerged, $\mathrm{KY}$ moved her left hand to her vagina, collected the placenta and started to feed on it immediately. At 09:46 she finished feeding on the placenta and started licking blood from her hands. She did not eat the umbilical cord and she left it hanging. At 09:48 she grasped the umbilical cord from the distal end and started pulling it. At 09:48:30 she was seen biting the umbilical cord. At 09:49 she stopped and after 30 sec she started feeding. At 09:53 NB (adult female) and her offspring joined the group on the tree. At 09: $55 \mathrm{KU}$ (adult female) and her offspring joined the group. At 10:16 KL (adult female) and her juvenile daughter joined the group. At 10:30 2 adult males (MU and AY) and a sub-adult female (JN) joined the group. None of the chimpanzees present showed any particular interest in the newborn infant.

\section{Observations during the Week Following the Birth}

The sex of the infant was identified as female and she was named KATIA (KA). During the first week of KA's life, KY and KA were observed daily. On each day they were seen with adult males, adult females, subadults, juveniles and infants, in large feeding parties on the Ficus. Apart from the initial interest of the juvenile male $\mathrm{KD}, 3 \mathrm{~min}$ after the birth, no interactions of any kind were observed between other party members and either KY or KA during the first week.

\section{Discussion}

This description of a live birth to a previously nulliparous female chimpanzee on a branch in a tree shows interesting features of labour and delivery, such as the eating of the placenta by the mother soon after it emerged It is also noteworthy that this birth took place high up $(30 \mathrm{~m})$ in a large tree, necessitating great care on the part of the mother, especially given the fact that this female had only one functional hand. Cleaning of the infant by the mother was not observed after delivery. The placenta and umbilical cord were eaten within $25 \mathrm{~min}$ of the birth. In contrast, of three infants seen at Gombe shortly after birth, two were still attached to the placenta for, in one case, "at least $36 \mathrm{hr}$ after the birth" (Goodall 1968:223).

The presence of other parous females with their offspring near the female giving birth is of note, as well as the positions taken by the female during labour, standing and sitting on a branch of a tree, and the use of her non-functional and her functional hands during the birth. It is also of interest that adult males were present in feeding parties with the new mother/infant pair, from $1 \mathrm{hr} 7 \mathrm{~min}$ after the birth onwards. No overt interest was shown in the infant by any other group members except for a brief moment $3 \mathrm{~min}$ after the birth when $\mathrm{KD}$ came close to see it.

\section{Acknowledgements}

I thank the late Tinka John for assistance during observations, and Lucilla Spini and Vernon Reynolds for assistance during the writing up of this report. I also thank Paula Pebworth for conducting the pregancy test. The chimpanzee research at Budongo was supported by National Geographic Society, while core funding for the Budongo Forest Project was provided by NORAD under its assistance to the Makerere University 
Department of Forestry. I also thank the Margot Marsh Foundation for additional support to the Project.

\section{Reference}

(1) Goodall J 1968. The behaviour of free-living chimpanzees in the Gombe Stream Reserve. Anim. Behav. Monographs. 1: Part 3. 